\title{
Effect of Ketamine in Pulmonary Hypertensive Children
}

\author{
Pokharel JN*, Upreti MR*, Shakya DR*, Regmi SR*, Shakya U*, Maskey A* \\ *Shahid Gangalal National Heart Centre, Kathmandu. \\ Corresponding: Dr. Jeju N. Pokharel, \\ Shahid Gangalal National Heart Centre, Bansbari, Kathmandu, Nepal, Tel: 00977-1-4371322, 00977-1-4371374., \\ Fax 00977-1-4371123, Email: jeju25@hotmail.com
}

Abstract

Pulmonary hypertension is not an uncommon condition in clinical setting. Pulmonary artery (PA) pressure may increase during anesthesia because of the hypoxia, hypoventilation and acidosis. Keeping these factors constant there are also other possibilities which can increase the PA pressure, for example drugs. Among them ketamine is known to increase PA pressure in adults especially when they have baseline increased PA pressure. In few literatures it is claimed that in children ketamine may be safe even in those with pulmonary hypertension.

We are using ketamine as a component of intravenous anesthesia in catheterization lab during right heart catheterization, pressure measurement and saturation evaluation. We thought it was necessary to evaluate the effect to ketamine on pulmonary artery pressure in pediatric patients in our setting. Altogether fifteen children diagnosed with pulmonary hypertension wer anesthetized with ketamine based anesthesia and the pulmonary artery pressure was evaluated in cardiac catheterization laboratory before and after 5, 10 and $15 \mathrm{~min}$ of injection of the ketamine $(2 \mathrm{mg} / \mathrm{kg}$ body weight) intravenously.

We found in our study only about $6.2 \%$ increment in pulmonary artery pressure after 5 minutes of the injection of the ketamine and the pressure came to the pre-injection level at 10 to 15 minutes of the injection In conclusion of this preliminary study with limited number of the cases, ketamine can be used safely without much problems in pulmonary hypertensive children secondary to the increased blood flow to the lungs.

Keywords : ketamine, pulmonary hypertension

\section{INTRODUCTION}

Rheumatic heart disease is the most important consequence of acute rheumatic fever. Rheumatic fever is non-suppurative complication of group A streptoccoccal pharyngitis due to a delayed immune response. Rheumatic fever usually occurs in childhood, affecting 5-15 year olds.

Rheumatic heart disease used to be a common cardiovascular problems of developed countries, which now continues to be a common health which now continues to be a common health problem in the developing world, causing morbidity and mortality among both children and adults. Rheumatic fever and rheumatic heart disease are common cardiovascular problems in Nepal.

Different school survey in Nepal reported the prevalence of rheumatic heart disease is high. Both rheumatic fever and rheumatic heart disease are more common in females.

However rheumatic heart disease can present in adults from aged 20 to 30 years. In $20 \%$ to $30 \%$ of such cases, there is no cardiac involvement, but patient often contract rheumatic fever more than once, and the damage is cumulative. Rheumatic heart valve lesion is progressive which lead to congestive cardiac failure.

Echocardiography is the important tool to detect rheumatic carditis and valvular morphology. 2D M-mode and doppler echocardiography can detect that valvular pathology, which is missed in clinical auscultation. It may over-diagnose trivial regurgitation because of its high snsitivity, and such trivial abnormalities, in the absence of any other abnormalities, can be disregarded.

The involvement of valves in rheumatic heart disease is very important from the therapeutic point of view. The treatment options depend upon the severity and type of valve involvement. This study aims to find out the pattern of involvement of heart valves and their severity.

\section{METHODOLOGY}

A total of 133 patients attending Dhulikhel Hospital with echocardiographically confirmed valvular heart disease between July 2008 to June 2009 were studied. Of this group 51 patients were having rheumatic heart disease. To be included in this group patients had either 1) a past history of rheumatic fever satisfying the revised Jones' criteria or 2) a pattern of morphological change on echocardiograpy consistent with a rheumatic heart disease causation once all other possible aetiologies had been excluded.

The transthoracic echocardiographic examination of the heart valves was performed with Toshiba Power Vision 6000 
Ketamine, a phencycline derivative, is confortable to use as an anaesthetic in many settings because it induces amnesia as well as analgesia in therapeutic as well as in diagnostic procedures. It is also very cheap and easily available in the country like ours. This drug is commonly used in many hospitals and clinics of our country. Similarly we are also commonly using low dose ketamine intravenously during induction of anesthesia in operation theater and ketamine as a component of total intravenous anesthesia in cardiac catheterization laboratory for pulmonary hypertensive children as well. One of the known side effect of the ketamine is that it increase the pulmonary artery pressure up to 40 to $50 \%$ from the baseline in adult patients with normal pulmonary artery pressure. But in normal children it does not increase or increases insignificantly. In pulmonary artery hypertensive children there may be risk of increase in the PApressure. In our setting we wanted to insure that whether ketamine in the dose we are using increase the PA pressure or not in the pulmonary hypertensive patients (children).

\section{METHOD}

Children below 14 years with acyanotic congental heart diseases like ventricular septal defect, patent ductus arteriosus or atrial septal defect with moderate to severe pulmonary hypertension (diagnosed in the bases of clinical features and echocardiography) scheduled for saturation evaluation and pressure measurements requiring general Anesthesia were subjected for the study. Patients were fasted at least two hours for clear fluid and six hours for solid food and milk and were not premedicated. Patients were taken to cath lab and vein cannulated (vein is opened earlier in patients below one year or to very ill looking patients to infuse intravenous dextrose in the preparation room or in the ward). ECG, NIBP with 5 minute interval and pulse oxymetry monitorng was done. The patient was injected with $50 \% \mathrm{DW} 1 \mathrm{ml} / \mathrm{kg}$, ceftriaxone $25 \mathrm{mg} /$ $\mathrm{kg}$, morphine $0.05 \mathrm{mg} / \mathrm{kg}$ or fentanyl $0.5 \mathrm{mcg} / \mathrm{kg}$, midazolam $0.05 \mathrm{mg} / \mathrm{kg}$ and propofol $2 \mathrm{mg} / \mathrm{kg} \mathrm{IV}$. Oxygen was given via face mask $4 \mathrm{I} / \mathrm{min}$. after that femoral venous access was taken after infiltarating the local anaesthetic into the groin. Then appropriate size of PA catheter was inserted and pressures were measured in superior venacava, inferior venacava, RA, RV, PA and wages pressure as well and samples were taken from the required sites

The patients received $2 \mathrm{mg} / \mathrm{kg}$ ketamine IV afterwards and PA pressure, heart rate, saturation and blood pressure were recorded every five minutes for fifteen minutes.

\section{RESULTS}

Sixteen cases of pulmonary hypertensive children has been studied till date and one of them had been omitted from the study because patient moved during femoral venous access at the beginning and had to inject ketamine before pressure measurement could be taken. We found from our study that the children receiving ketamine for general Anesthesia during cardiac catheterization study only about $6.2 \%$ increase in mean pulmonary artery pressure in the first few minutes and which normalized to the baseline within 10 to $15 \mathrm{~min}$ of the injection. This shows that out usual technique using ketamine in combination with opioid and midazolam is not harmful to the pulmonary hypertensive children in terms of the PA pressure. Although the number of the cases is very limited to make some recommendations but the study is on going and findings will be published at a later date.

\section{DISCUSSION}

Pulmonary hypertension is not a rarely encountered clinical condition in acyanotic congenital heart disease patients. Pulmonary artery pressure (PAP) may increase during Anesthesia due to hypoxia, hypercarbia and acidosis. Somehow these factors can be controlled during Anesthesia. But there are some other possibilities which may increase the PA pressure, for example drugs. Among the drugs ketamine is very commonly used in out cath lab to anaesthetize the children requiring general anesthesia.

Haemodynamic effect of the ketamine is studied in many publications. Ketamine is easily available drug which induces amnesia and analgesia with preserving shunt fraction in congenital heart disease children.

In adults it may increase pulmonary artery pressure upto $40-50 \%$ from the baseline. In children it dies not increase the PA pressure. In pulmonary hypertensive children it may increase the PA pressure.

In out obsetvationn and study we found that ketamine increased only about $6.2 \%$ of PA pressure from the baseline even in the pulmonary hypertensive children.

It shows that use of ketamine in pulmonary hypertensive children is not harmful in terms of PA pressure when it is used as a component of total intravenous Anesthesia.

\section{CONCLUSION}

Ketamine is commonly used drug in our setting during anethesia care in the cath lab because it is easily available. Cheap and maintains haemodynamic stability in our usual dose as a component of total intravenous Anesthesia.

Ketamine did not cause marked increase in PA pressure in moderate to severe pulmonary hypertensive children.

\begin{tabular}{|c|c|c|c|c|c|}
\hline $\begin{array}{c}\text { Case } \\
\text { No }\end{array}$ & Age & $\begin{array}{c}\text { Base line } \\
\text { PAP } \\
\text { mmHg }\end{array}$ & $\begin{array}{c}\text { PAP } \\
\mathrm{mmHg} \\
\text { at } 5 \mathrm{~min}\end{array}$ & $\begin{array}{c}\mathrm{PAP} \\
\mathrm{mmHg} \\
\text { at } 10 \mathrm{~min}\end{array}$ & $\begin{array}{c}\mathrm{PAP} \\
\mathrm{mmHg} \\
\text { at } 15 \\
\text { min }\end{array}$ \\
\hline 1 & $9 y$ & 64 & 62 & 65 & 65 \\
\hline 2 & $20 \mathrm{mo}$ & 39 & 37 & 38 & 37 \\
\hline 3 & $6 y$ & 79 & 81 & 79 & 77 \\
\hline 4 & $12 \mathrm{y}$ & 55 & 60 & 60 & 59 \\
\hline 5 & $30 \mathrm{mo}$ & 51 & 65 & 59 & 50 \\
\hline 6 & $5 \mathrm{y}$ & 68 & 71 & 68 & 65 \\
\hline 7 & $8 \mathrm{y}$ & 64 & 75 & 66 & 73 \\
\hline 8 & $8 \mathrm{y}$ & 63 & 61 & 60 & 58 \\
\hline 9 & $2 y$ & 63 & 61 & 64 & 60 \\
\hline 10 & $2 \mathrm{mo}$ & 54 & 51 & 50 & 50 \\
\hline 11 & $9 y$ & 70 & 67 & 81 & 75 \\
\hline 12 & $5 \mathrm{y}$ & 47 & 65 & 69 & 71 \\
\hline \multirow[t]{2}{*}{13} & $18 \mathrm{mo}$ & 48 & 50 & 45 & 45 \\
\hline & $2 y$ & 46 & 52 & 60 & 65 \\
\hline 15 & $8 \mathrm{mo}$ & 33 & 38 & 33 & 37 \\
\hline \multicolumn{2}{|l|}{ Mean } & 56.2 & 59.7 & 57.1 & 54.8 \\
\hline
\end{tabular}




\section{REFERENCES}

1. MorrayJP, Lynn AM, Stamm SJ, et al: Hemodynamic effects of ketamine in children with congenital heart disease. Anesthesia and Analgesia 1984; 63: 895.

2. Faithful NS, Haider R: Ketamine for cardiac catheterization: an evaluation of its use in children. Anesthesia 1971;26: 318

3. Gassner S, Cohen M, Aygen M, et al The effect of ketamine on pulmonary artery pressure. Anesthesia 1974; 29: 141

4. Hickey PR, Hansen DD, Cromolini GM, et al: Pulmonary and systemic haemodynamic responses to ketamine in infants with normal and elevated pulmonary vascular resistance. Anesthesiology 1985; 62: 287.

5. Kaplan JA, Cardiac Anesthesia, Third edition 1993.
6. Coppel DL, Dundee JW, Ketamine anesthesia for cardiac catheterization. Anesthesia 1972;27:25-31.

7. White PF, way WL, Trevor AJ, Ketamine pharmacology and therapeutic uses Anesthesiology 1982; 56: 119-36.

8. Hollester GR, Burn JMB, Side effects of ketamine in pediatric anesthesia. Anesth Analg 1974; 53: 264-67.

Primary Percutaneous Coronary Intervention (PPCI) in Acute Myocardial Infarction Complicated by Cardiogenic Shock in a Newly Emerging Cardiac Centre in Nepal

Maskey A*, Regmi SR*, Bhatt $\mathrm{Y}^{*}$, Malla $\mathrm{R}^{*}$, Rajbhandari $\mathrm{R}^{*}$, Sharma D*, K.C. MB*, Limbu YR*, Dubey L*

*Department of Cardilogy, Shahid Gangalal National Heart Centre 